\title{
EFECTIVIDAD DEL ÁCIDO FÓRMICO Y EL TIMOL EN EL CONTROL DEL ÁCARO Varroa destructor EN COLMENAS DE ABEJAS AFRICANIZADAS
}

\author{
Rafael A. Calderón ${ }^{1 / *}$, Marianyela Ramírez, Fernando Ramírez, Ethel Villalobos ${ }^{* *}$ \\ Palabras clave: Ácido fórmico, timol, Varroa destructor, abejas africanizadas. \\ Keywords: Formic acid, thymol, Varroa destructor, africanized honeybees.
}

Recibido: $15 / 04 / 13$

\section{RESUMEN}

Se evaluó la efectividad del ácido fórmico y el timol en el combate del ácaro Varroa destructor en colmenas de abejas africanizadas, de junio a octubre 2011, en un apiario constituido por 16 colmenas (las cuales no recibieron tratamiento químico previo al estudio) y ubicado en Atenas, Alajuela. El apiario se dividió en 3 grupos seleccionados al azar (A, B y C) de 8,5 y 3 colmenas, respectivamente. El grupo A fue tratado con $150 \mathrm{~g}$ de ácido fórmico al 65\%, en el grupo B se hicieron 2 aplicaciones de $25 \mathrm{~g}$ de timol y el grupo C se utilizó como testigo. Para colectar los ácaros se colocó una trampa en el fondo de cada colmena. Al final de los tratamientos se aplicaron 4 tiras de flumetrina para eliminar los ácaros remanentes y determinar la efectividad de los productos. Además, se evaluó la mortalidad de los diferentes estadios de varroa en cría sellada de obrera, para lo cual se revisó la pupa y el fondo de la celda. La efectividad del ácido fórmico y el timol en el combate de varroa fue de un $94,7 \%$ y $96,9 \%$ respectivamente. En las colmenas tratadas con ácido fórmico la mortalidad de varroa se dio principalmente en las primeras $72 \mathrm{~h}$ de aplicación, mientras que al aplicar

1 Autor para correspondencia. Correo electrónico: rafael.calderon.fallas@una.cr

* Programa Integrado de Patología Apícola, Centro de Investigaciones Apícolas Tropicales, Universidad Nacional, Heredia, Costa Rica.
Aceptado: 06/08/13

\begin{abstract}
Effectiveness of formic acid and thymol in the control of Varroa destructor in africanized honey bee colonies. The effectiveness of formic acid and thymol in the control of the mite Varroa destructor was evaluated from June to October 2011 in an apiary of 16 Africanized honeybee colonies (the colonies did not receive chemical treatment at all) located in Atenas, Alajuela. The apiary was randomly divided in three groups (A, B and C) of 8, 5 and 3 colonies, respectively. Group A was treated with $150 \mathrm{~g}$ of formic acid at $65 \%$, group B received 2 applications of 25 $\mathrm{g}$ thymol and colonies of group $\mathrm{C}$ were used as control. Varroa traps were placed on the bottom board of each colony to collect the mites. After 4 weeks, all colonies were treated with 4 strips of flumethrin to kill the remaining mites and to assess the effectiveness of the products. Furthermore, the mortality of the different stages of varroa was evaluated in capped worker brood cells checking the pupa and the bottom of the cell for mites. The effectiveness of formic acid and thymol in the control of varroa mites was $94.7 \%$ and $96.9 \%$ respectively. In colonies treated with formic acid varroa mortality occurred mainly during $72 \mathrm{~h}$ after application, meanwhile in the

\footnotetext{
** Department of Plant and Environmental Protection Sciences, University of Hawaii at Manoa, The United States.
} 
timol se observó una semana después. Se determinó una mortalidad del $86 \%$ en los diferentes estadios de varroa en la cría sellada de obrera luego de aplicar ácido fórmico, mientras que en las colmenas tratadas con timol y en el grupo testigo, la mortalidad de ácaros fue menor a un $10 \%$. En conclusión, se determinó una alta efectividad del ácido fórmico y el timol en el combate de varroa, por lo que ambos productos pueden ser considerados como una alternativa en el manejo integrado de varroa en colmenas de abejas africanizadas.

\section{INTRODUCCIÓN}

Las abejas melíferas (Apis mellifera) son afectadas por distintos agentes etiológicos como virus, bacterias, hongos y parásitos. Se han descrito más de 35 enfermedades asociadas a esta especie de abejas, la mayoría ocasiona daños considerables en la apicultura mundial (Ritter 2001). Una de las enfermedades de mayor importancia económica es la Varroosis, causada por el ácaro Varroa destructor, el cual parasita tanto a la cría, como a las abejas adultas (Bailey y Ball 1991, Espina y Ordetx 1984).

A la fecha, $V$. destructor se encuentra distribuido a nivel mundial, con excepción de Australia. En Costa Rica fue detectado el 26 de setiembre de 1997 (Calderón et ál. 1998). Productores de diferentes regiones del país han indicado la pérdida de colmenas y una reducción en la producción de miel, debido a la presencia de varroa en las abejas, lo que indica que es un problema serio para la apicultura nacional (Calderón 2009). Uno de los principales aspectos relacionados con varroa, es el daño infeccioso asociado a la transmisión de agentes virales, como el virus que deforma las alas, el virus Kashmir y el virus de la parálisis aguda, los cuales ocasionan un debilitamiento de la colmena y en ciertos casos la pérdida (Bailey y Ball 1991, Ritter 2001). group treated with thymol the mite mortality was observed mainly one week after treatment. In addition, in the group of colonies treated with formic acid $86 \%$ of mite mortality occurred in capped brood cells, while in colonies treated with thymol and control colonies the varroa mortality in capped cells was less than $10 \%$. In conclusion, the effectiveness of formic acid and thymol in the control of varroa mites was high, for which reason both products can be considered an alternative for the integrated management of varroa mites in Africanized honeybees colonies.

Varroa se reproduce exclusivamente en la cría sellada (Ritter 2001, Vandame 2000). El ácaro ingresa a la celda con cría poco antes de ser operculada (Vandame 2000), se traslada hasta el fondo de la misma, donde permanece en el alimento larval. Una vez que las obreras operculan la celda, el ácaro se desplaza hacia la larva e inicia su alimentación (hemolinfa de la larva) (Ritter 2001). Aproximadamente $60 \mathrm{~h}$ después de operculada la celda, la hembra pone el primer huevo, el cual da origen al macho, mientras que los siguientes huevos son ovipositados a intervalos de $30 \mathrm{~h}$ y de ellos emergen hembras. El desarrollo del macho tarda aproximadamente de 6 a 6,5 días, mientras que la hembra de 5,5 a 6 días (Bailey y Ball 1991).

Existen diferentes productos para el tratamiento de la Varroosis, dentro de ellos los acaricidas químicos son los más utilizados, principalmente los piretroides, como el fluvalinato $\left(\right.$ Apistan $^{\circledR}$ ) y la flumetrina $\left(\right.$ Bayvarol $\left.^{\circledR}\right)$. Las ventajas de estos productos, son la alta eficiencia en el combate de varroa y la presentación en tiras plásticas, lo cual facilita la aplicación en las colmenas (Bailey y Ball 1991). Sin embargo, el uso inadecuado e indiscrimado de estos acaricidas, como la subdosificación y el uso de preparaciones caseras, han provocado que el ácaro desarrolle resistencia (Kanga et ál. 2010, Milani 1995, Trouiller 1998). 
Además los acaricidas químicos pueden contaminar los productos de la colmena, como la miel y la cera, con residuos que pueden afectar la salud del consumidor (Al-Rifai y Akeel 1997, Tsigouri et ál. 2003, Wallner 1999). Asimismo, la adquisición representa un valor elevado para los apicultores, lo que aumenta los costos de producción.

Esta problemática ha conllevado al estudio de métodos de manejo integrado para el tratamiento de varroa, con la finalidad de reducir la aplicación de acaricidas químicos. Actualmente, se investiga la selección de abejas resistentes a varroa como un método de combate (Büchler et ál. 2010, Rinderer et ál. 2010). También, se ha investigado el uso de productos alternativos de bajo impacto ambiental, como el timol (aceite esencial), sustancia natural derivada de la planta del tomillo, y el ácido fórmico (ácido orgánico), presente en insectos como las hormigas. El uso del timol tiene la ventaja de presentar baja toxicidad y un reducido impacto ambiental (Adamczyk et ál. 2005, Bogdanov 2006). Mientras que una de las principales ventajas del ácido fórmico, es que se encuentra naturalmente en pequeñas cantidades en la miel, por lo que no se considera contaminante (Bogdanov 2006, Eguaras et ál. 2003). Además, elimina los ácaros que se encuentran sobre las abejas adultas (foréticos) y los que se reproducen en la cría sellada (Calis et ál. 1998). A la fecha, no se ha indicado que varroa desarrolle resistencia a estos productos alternativos (Mitchell y Vanderdussen 2010).

La efectividad del ácido fórmico y el timol en el combate de varroa ha sido estudiada en abejas de tipo europeo y en países con condiciones de clima templado, mientras que la investigación en abejas africanizadas y en condiciones tropicales es muy escasa (Baggio et ál. 2004, Eguaras et ál. 2003, Gregorc y Planinc 2005, Satta et ál. 2005). En nuestro país, se han realizado ensayos preliminares con aplicaciones de estos productos de manera tradicional (en forma líquida y en cristales), y se han obtenido resultados favorables (Calderón et ál. 2000a). Sin embargo, al actuar por evaporación la efectividad de ambos productos se ve afectada por condiciones de temperatura y humedad ambiental (Emsen et ál. 2007, Ritter 1993). Por lo anterior, en los últimos años se ha tratado de mejorar los métodos de aplicación del ácido fórmico y el timol, con la finalidad de aumentar la efectividad en el tratamiento de varroa y disminuir el impacto sobre la colmena (Feldlaufer et ál. 1997). Recientemente se han desarrollado productos como el Mite Away Quick Strips $\left(\mathrm{MAQS}^{\circledR}\right.$ ) y el Apiguard ${ }^{\circledR}$, formulaciones de ácido fórmico y timol respectivamente, en una base de gel. El gel permite una evaporación controlada del ingrediente activo, lo cual mejora la efectividad de los acaricidas sin causar daño severo a las abejas (Mitchel y Vanderdussen 2010, Trouiller 2004). Se han reportado resultados favorables en la eliminación de ácaros foréticos y la mortalidad de ácaros en la cría sellada en abejas de tipo europeo con el producto MAQS ${ }^{\circledR}$ (Van Alten et ál. 2009, Villalobos 2010).

Debido a la escasa información relacionada con el tratamiento del ácaro $V$. destructor en abejas africanizadas en Costa Rica, es necesario evaluar la efectividad de productos alternativos, como el ácido fórmico y el timol. Lo cual permitirá desarrollar programas de manejo integrado de varroa, dirigidos a reducir la aplicación de acaricidas químicos y el impacto negativo en el ambiente, disminuir los costos de producción y la presencia de residuos químicos en la miel, polen, cera y propóleo. Específicamente el presente estudio beneficiará a los productores de miel orgánica, ya que los acaricidas para el tratamiento de varroa aceptados en apicultura orgánica, son escasos.

\section{MATERIALES Y MÉTODOS}

El estudio se realizó en un apiario experimental constituido por 16 colmenas de abejas africanizadas (A. mellifera), ubicado en el Cantón de Atenas, provincia de Alajuela $\left(9^{\circ} 58^{\prime} \mathrm{N}, 84^{\circ} 24\right.$ O, $700 \mathrm{msnm}$ ), clasificado como bosque húmedo premontano, con una temperatura promedio de $23,7^{\circ} \mathrm{C}$. El mismo se llevó a cabo de junio a octubre 2011 (época lluviosa), meses en los cuales hay una mayor incidencia del ácaro varroa (Calderón et ál. 2007). 
Las colmenas estaban conformadas por aproximadamente 8 panales y una abeja reina joven (menor de 6 meses). El manejo de las colmenas fue similar al que se realiza en un apiario comercial, se alimentaron con jarabe de azúcar (una parte de azúcar y una parte de agua), una vez por semana durante el estudio.

Productos evaluados: Se evaluó la efectividad de los productos MAQS ${ }^{\circledR}$ (ácido fórmico) y Apiguard $^{\circledR}$ (timol) en el combate del ácaro varroa.

a. $\quad$ El producto MAQS ${ }^{\circledR}$ consiste en un gel orgánico formulado en tiras de $150 \mathrm{~g}$ con ácido fórmico al $65 \%$, las cuales se colocan sobre los marcos de la cámara de cría.

b. $\quad$ El acaricida Apiguard ${ }^{\circledR}$ es un gel que contiene timol al 25\%. El gel permite una liberación gradual del ingrediente activo, lo cual reduce el daño a la colmena y mejora el combate de la Varroosis (Trouiller 2004). Una de las presentaciones comerciales es en paquetes de $25 \mathrm{~g}$.

Descripción de los tratamientos: El apiario se dividió en 3 grupos seleccionados al azar (A, B y C), conformados por 8,5 y 3 colmenas, respectivamente.

Grupo A: Estas colmenas fueron tratadas con el producto MAQS ${ }^{\circledR}$. Se aplicó una tira (150 g) por colmena, la cual se dividió en 2 partes, colocadas diagonalmente sobre los marcos de la cámara de cría y separadas por una distancia de $25 \mathrm{~cm}$ entre ellas. A cada colmena se le colocó un marco de madera en la parte superior, para proporcionar un espacio de $1,0 \mathrm{~cm}$ entre el gel y la tapa. Se realizó una sola aplicación del producto, el cual permaneció en la colmena durante 4 semanas. Debido a que el ácido fórmico tiene efecto sobre los ácaros que se encuentran en la cría operculada, se esperó a que la cría de obrera completara el estadio de pupa (fase sellada=12 días) y emergiera de la celda como abeja adulta, para colectar los ácaros que caen al piso de la colmena por efecto del ácido. Posterior al tratamiento con
MAQS ${ }^{\circledR}$, se aplicó 4 tiras de Bayvarol ${ }^{\circledR}(3,6 \mathrm{mg}$ de flumetrina por tira), las cuales se mantuvieron por 4 semanas (efectividad conocida superior al 98\%), con el fin de eliminar los ácaros que no murieron con el tratamiento anterior (Calderón et ál. 2000a).

Grupo B: Este grupo de colmenas se trataron con el producto Apiguard ${ }^{\circledR}$. Se aplicó un paquete de $25 \mathrm{~g}$ de gel en una lámina de cartulina de 12 x $9 \mathrm{~cm}$ colocada sobre los marcos de la cámara de cría (panales donde la reina realiza la postura de huevos y se da el desarrollo de la cría, se ubican en el centro de la colmena). Se realizaron 2 aplicaciones de Apiguard $^{\circledR}$, la primera al día uno y la segunda al día 15 . El tratamiento completo fue de $50 \mathrm{~g}$ de Apiguard ${ }^{\circledR}$ por colmena con una duración de 30 días. Adicionalmente, a cada colmena se le adaptó un marco de madera en la parte superior, que proporcionó un espacio de $1,0 \mathrm{~cm}$ entre el producto y la tapa, que facilitó la evaporación del timol. Además, el espacio permitió a las obreras tener contacto con el gel, el cual se adhiere al cuerpo de la abeja y mientras realiza diversas actividades lo distribuye en la colmena. Asimismo, por el comportamiento de limpieza, otras obreras participan en la remoción del timol contribuyendo a su dispersión (Bogdanov 2006). Una vez finalizado el tratamiento con Apiguard ${ }^{\circledR}$, se aplicó 4 tiras de Bayvarol ${ }^{\circledR}$ (para eliminar los ácaros restantes) por un periodo de 4 semanas.

Grupo C: Este grupo de colmenas se utilizó como testigo para evaluar la mortalidad natural de ácaros, por lo que no se aplicó ningún producto durante los primeros 30 días. Posteriormente, al igual que en los grupos A y B, se aplicó 4 tiras de Bayvarol ${ }^{\circledR}$ durante 4 semanas.

Colecta de ácaros: Para colectar los ácaros durante los tratamientos, se colocó una trampa en el piso de cada colmena. Esta trampa consistió en un fondo de madera $(50 \times 42 \mathrm{~cm})$, cubierto con un cedazo metálico en la parte superior, el tamaño del tamiz fue de 6 agujeros por $\mathrm{cm}^{2}$, el cual permitió el paso de los ácaros, y a su vez impidió que las abejas los removieran. En el interior de 
cada trampa se colocó una lámina de cartulina blanca impregnada con vaselina y previamente cuadriculada para facilitar el conteo de los ácaros. Para evitar disturbar las abejas, la cartulina se introdujo por la parte posterior de la colmena. Inicialmente las láminas permanecieron por $24 \mathrm{y}$ $72 \mathrm{~h}$, posteriormente se reemplazaron cada 7 días. Las láminas se llevaron al laboratorio de Patología Apícola, donde se realizó el conteo de los ácaros.
Efectividad de los tratamientos: Para determinar la efectividad de los productos (MAQS $^{\circledR}$ y Apiguard $^{\circledR}$ ), se cuantificó la mortalidad de ácaros con su aplicación y con el Bayvarol ${ }^{\circledR}$, para ambos conteos que representan aproximadamente el total de ácaros presentes en la colmena.

El porcentaje de efectividad se obtuvo con la siguiente fórmula:

$$
\text { Porcentaje de efectividad }=\frac{\text { Total de ácaros caídos con MAQS }^{\circledR} \text { o Apiguard }}{\text { Total de ácaros caídos en la colmena }^{\circledR}} \text { X } 100
$$

Mortalidad de ácaros en la cría sellada:

Se analizó la mortalidad del ácaro madre y su descendencia (protoninfa, deutoninfa, macho y hembra), en cría operculada de obrera. Se tomó una muestra de panal $(10 \times 10 \mathrm{~cm})$ con cría sellada de obrera, proveniente de las colmenas tratadas con ácido fórmico, timol y colmenas del grupo testigo. Las muestras se colectaron a las 24 y $72 \mathrm{~h}$ luego de iniciado los tratamientos y se trasladaron al laboratorio para su análisis. Se removió el opérculo de la celda con una pinza de punta fina, se retiró la pupa de la celda y se colocó en una placa de petri. Además, con una lupa con fuente de luz se revisó cuidadosamente el fondo de la celda para determinar la presencia de ácaros (maduros e inmaduros). Con la finalidad de determinar la condición (mortalidad) de los diferentes estadios, los ácaros se sacaron de la celda y se examinaron con un estereoscopio (10x).

Para cada celda analizada se registró la etapa de desarrollo de la pupa de la abeja, el total de ácaros adultos, así como la cantidad y el estadio de desarrollo de la cría. Para clasificar la etapa de desarrollo (estadios maduros e inmaduros de varroa), se tomó como referencia el desarrollo ontogénico señalado por Martin (1994, 1995). Los diferentes estadios del ácaro se clasificaron como huevo-larva, protoninfa, deutoninfa, macho e hija adulta (Ifantidis 1997).
La mortalidad de los diferentes estadios del ácaro se comprobó según los siguientes parámetros indicados por Ifantidis (1997):

Un ácaro no es viable si presenta deformaciones o alteraciones en el cuerpo. Por ejemplo, se observan deshidratados y con apariencia plegada.

Los estadios móviles (protoninfa móvil, deutoninfa móvil, macho, hija adulta y ácaro madre adulto) que no presenten movimiento en las extremidades, son considerados muertos.

La mortalidad de los estadios inmóviles, especialmente la deutoninfa, se establece por la pérdida de movimiento peristáltico en los túbulos de Malpighi (se revisaron en el estereoscopio a un aumento de 7x). En condiciones normales, los túbulos se encuentran bien formados y son visibles a través del integumento.

La mortalidad de la deutoninfa inmóvil durante el proceso de muda, es reconocida por la ausencia de movimiento de las extremidades, las cuales se observan contraídas contra el opistoma.

Análisis de los resultados: Para comparar la mortalidad de ácaros entre tratamientos se utilizó la prueba LSD (diferencias mínimas significativas para separación de medias de tratamiento) con un nivel de significancia de 0,05. Además, al considerar el tiempo como un factor, se utilizó el análisis interacción-tiempo, para 
determinar diferencias significativas en la mortalidad de ácaros de un mismo tratamiento durante la evaluación.

\section{RESULTADOS}

Se obtuvo una alta efectividad del ácido fórmico y el timol en el tratamiento del ácaro varroa en colmenas de abejas africanizadas. Adicionalmente, el ácido fórmico presentó efectividad en el combate de ácaros en las celdas con cría sellada.

\section{Efectividad del ácido fórmico} $\left(\mathbf{M A Q S}^{\circledR}\right)$ : El promedio de ácaros caídos en las colmenas tratadas con ácido fórmico correspondió a $1065 \pm 118 \quad(n=8)$. Un 58\% fue eliminado durante el primer día de tratamiento, con un promedio de $621 \pm 83$ ácaros por colmena. Al tercer día de muestreo, se observó una reducción significativa en la colecta de varroa $(\mathrm{p}<0,0001)$. Asimismo, al día 15 de tratamiento se obtuvo una mortalidad de $127 \pm 52$ ácaros hasta disminuir al día 30 (cuarta semana) de evaluación ( $\mathrm{p}<0,0001)$. Posteriormente, al aplicar la flumetrina (Bayva$\left.\mathrm{rol}^{\circledR}\right)$ se eliminaron $59 \pm 22(\mathrm{n}=8)$ ácaros. Si se considera la mortalidad total, se puede indicar que la efectividad del ácido fórmico (MAQS ${ }^{\circledR}$ ) en el tratamiento del ácaro $V$. destructor en colmenas de abejas africanizadas correspondió a un 94,7\% (Cuadro 1).

Cuadro 1. Ácaros colectados con la aplicación del ácido fórmico en colmenas de abejas africanizadas (n=8) en un periodo de 30 días (Promedio \pm ES).

\begin{tabular}{cccccccccc}
\hline Periodo muestreo (días) & 1 & 3 & 8 & 15 & 22 & 30 & Total & Flum & Efect \% \\
\hline Ácaros caídos & $621 \pm 83$ & $181 \pm 65$ & $128 \pm 41$ & $127 \pm 52$ & $5 \pm 1$ & $4 \pm 1$ & $1065 \pm 118$ & $59 \pm 22$ & 94,7 \\
\hline
\end{tabular}

Flum= Flumetrina.

Efect $=$ Efectividad.

Distribución de la mortalidad de ácaros:

En la mayoría de colmenas al aplicar el ácido fórmico, la mortalidad de ácaros ocurrió principalmente durante el primer día de tratamiento (ácaros foréticos) (Figuras 1 y 2). En ciertas colmenas $(\mathrm{n}=3)$ la mortalidad de ácaros disminuyó drásticamente a partir del tercer día (primera semana), con un promedio menor a 55 ácaros durante los siguientes 15 días, hasta finalizar el tratamiento con 2 ácaros por colmena (Figura 1).

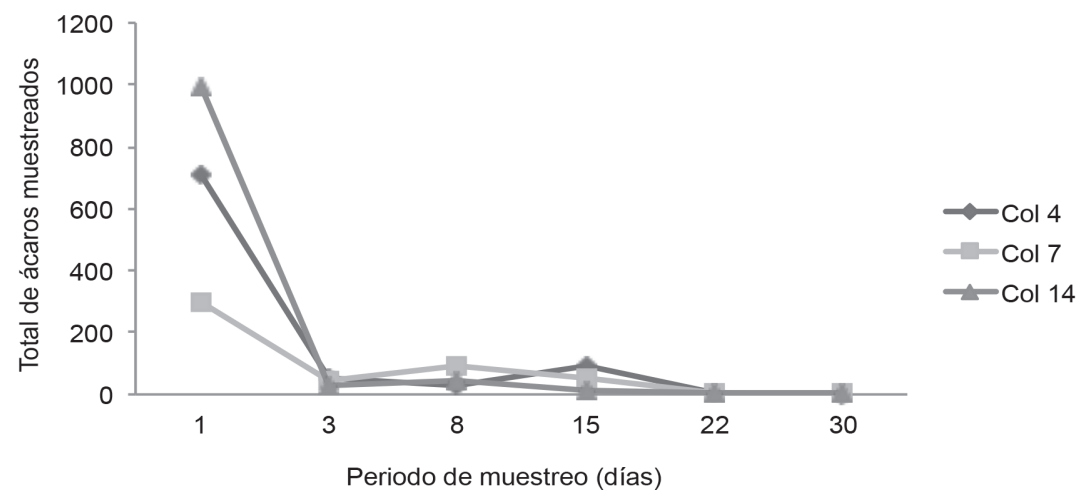

Fig. 1. Colmenas con mayor mortalidad de ácaros durante los primeros 3 días de tratamiento con ácido fórmico. 


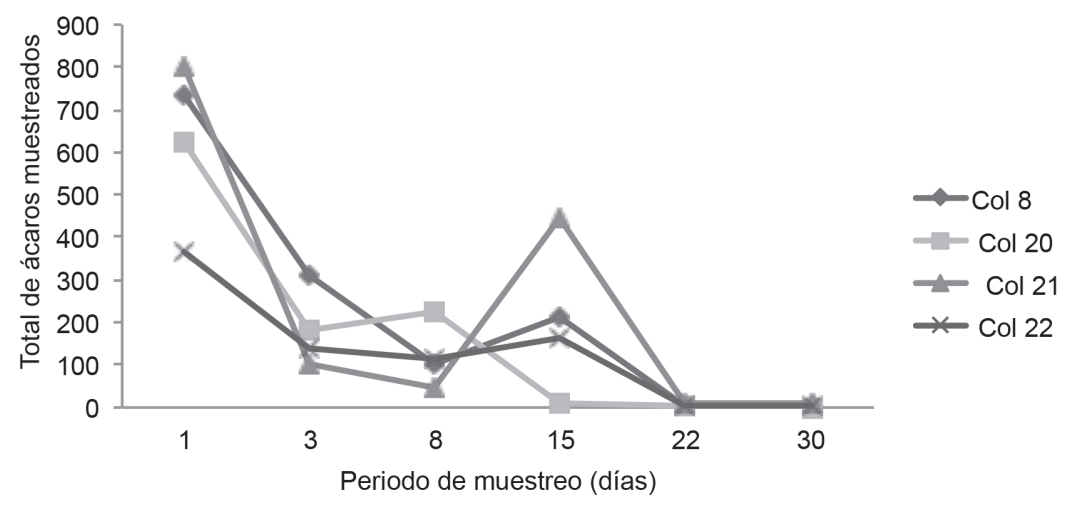

Fig. 2. Colmenas con una mortalidad considerable de ácaros durante las primeras $24 \mathrm{~h}$ y la segunda semana de tratamiento con ácido fórmico.

Por otra parte, en un grupo de colmenas $(n=4)$ la mortalidad de ácaros también se redujo posterior a la primera semana (día 8), sin embargo durante la segunda semana de tratamiento (día 15) se presentó un aumento en la mortalidad, con un promedio de 207 ácaros por colmena (Figura 2).

Efectividad del timol (Apiguard ${ }^{\circledR}$ ): $\mathrm{Al}$ aplicar el timol, la mayor mortalidad de varroa se produjo durante la primera semana, con un promedio de $595 \pm 110$ ácaros $(\mathrm{n}=5)$, mientras que en la segunda semana disminuyó a $143 \pm 68$ ácaros ( $\mathrm{p}=0,0368)$. Al realizar la segunda aplicación de timol, la mortalidad fue de $158 \pm 45$ ácaros (17\%), reduciéndose considerablemente durante la última semana de tratamiento (día 30) $(\mathrm{p}=0,0009)$ (Cuadro 2).

Cuadro 2. Mortalidad de ácaros colectados durante la aplicación del timol en colmenas de abejas africanizadas ( $\mathrm{n}=5)$ en un periodo de 30 días (Promedio \pm ES).

\begin{tabular}{cccccccccc}
\hline Periodo muestreo (días) & 1 & 3 & 8 & 15 & 22 & 30 & Total & Flum & $\%$ Efect \\
\hline Ácaros caídos & $53 \pm 15$ & $191 \pm 60$ & $351 \pm 88$ & $143 \pm 68$ & $158 \pm 45$ & $11 \pm 4$ & $905 \pm 210$ & $29 \pm 9$ & 96,9 \\
\hline
\end{tabular}

Flum= Flumetrina.

Efect $=$ Efectividad

Al aplicar la flumetrina $\left(\right.$ Bayvarol $\left.^{\circledR}\right)$ se colectó un total de $29 \pm 9$ ácaros. Lo anterior permite establecer que el porcentaje de efectividad del timol (Apiguard ${ }^{\circledR}$ ) en el manejo del ácaro $V$. destructor en colmenas de abejas africanizadas fue de $96,9 \%$ (Cuadro 2).
Distribución de la mortalidad de ácaros: Con la aplicación del timol se registró un aumento gradual en la mortalidad de varroa, a diferencia de lo que se observó en las colmenas tratadas con ácido fórmico, en las cuales la mortalidad de ácaros ocurrió principalmente 
en las primeras $72 \mathrm{~h}$ (Figura 3). Durante el primer día de aplicación del producto, se observó una ligera mortalidad de ácaros, la cual aumentó en la mayoría de colmenas, hasta un máximo de 351 ácaros al octavo día. Únicamente en la colmena 13 la mayor mortalidad de ácaros se dio al tercer día de muestreo. Posterior a la segunda aplicación del timol, en ciertas colmenas se registró un incremento moderado en la mortalidad de varroa, hasta descender en la última semana de tratamiento (Figura 3).

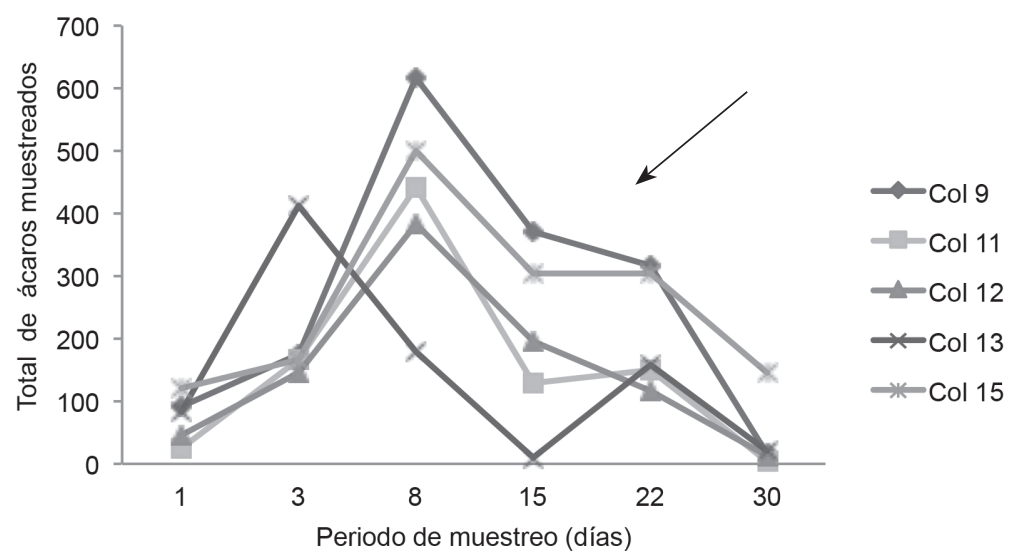

Fig. 3. Distribución de la mortalidad de ácaros en las colmenas tratadas con timol. La flecha indica la segunda aplicación de timol.

Mortalidad natural de varroa en las colmenas testigo: La mortalidad de varroa fue de $715 \pm 531$ ácaros durante un periodo de 30 días. La mayor cantidad de ácaros se registró al día 22 , colectándose $335 \pm 285(\mathrm{n}=3)$, mientras que la menor cantidad se obtuvo el primer día de muestreo con $30 \pm 13$ ácaros. Al aplicar la flumetrina $\left(\right.$ Bayvarol $^{\circledR}$ ), se eliminaron $2072 \pm 1874$ ácaros remanentes en las colmenas testigo. El porcentaje de ácaros caídos en forma natural correspondió a un $25,7 \%$ de los ácaros presentes en las colmenas (Cuadro 3).

Cuadro 3. Mortalidad natural de varroa en colmenas de abejas africanizadas $(n=3)$. (Promedio \pm ES).

\begin{tabular}{|c|c|c|c|c|c|c|c|c|c|}
\hline $\begin{array}{c}\text { Periodo de } \\
\text { muestreo (días) }\end{array}$ & 1 & 3 & 8 & 15 & 22 & 30 & Total & Flum & $\begin{array}{c}\text { Mortalidad } \\
\text { natural } \\
(\%)\end{array}$ \\
\hline Ácaros caídos & $30 \pm 13$ & $55 \pm 45$ & $79 \pm 46$ & $67 \pm 57$ & $335 \pm 285$ & $149 \pm 131$ & $715 \pm 531$ & $2072 \pm 1874$ & 25,7 \\
\hline
\end{tabular}

Flum=Flumetrina.

Mortalidad de varroa en celdas con cría sellada de obrera: Se debe indicar que en un número considerable de celdas con pupas en fase temprana de desarrollo, se encontró únicamente la presencia del ácaro madre (no había iniciado el ciclo reproductivo).
Acido fórmico: Luego de aplicar el ácido fórmico, se observó un 95\% de mortalidad del ácaro madre en la cría sellada (Cuadro 4). Esta mortalidad se registró tanto a las $24 \mathrm{~h}$, como a las $72 \mathrm{~h}$ después de la aplicación del producto. Al analizar la mortalidad del macho de varroa, se 
Cuadro 4. Mortalidad (\%) de los diferentes estadios del ácaro varroa en celdas con cría sellada de obrera al aplicar ácido fórmico $\left(n^{*}=263\right)$, timol $(n=59)$ y en colmenas testigo $(n=315)$.

\begin{tabular}{lccc}
\hline Estadio del ácaro & $\begin{array}{c}\text { Acido fórmico } \\
(\%)\end{array}$ & $\begin{array}{c}\text { Timol } \\
(\%)\end{array}$ & $\begin{array}{c}\text { Testigo } \\
(\%)\end{array}$ \\
\hline Madres & 95 & 9 & 7 \\
Protoninfas & 88 & 9 & 5 \\
Deutoninfas & 41 & 6 & 5 \\
Hembras & 78 & 33 & 6 \\
Machos & 84 & 11 & 16 \\
\hline
\end{tabular}

$*_{\mathrm{n}}=$ corresponde a las celdas infestadas con el ácaro varroa que se analizaron para determinar mortalidad.

encontró que un $84 \%$ estaban muertos y fue uno de los estadios que presentó mayor mortalidad luego de aplicar el ácido fórmico. Por otro lado, el estadio en el que se observó menor mortalidad fue la deutoninfa (Cuadro 4).

Timol: En la cría sellada de las colmenas tratadas con timol, se determinó una baja mortalidad del ácaro madre, observándose la mayoría de ácaros en buenas condiciones. Solamente un 9\% de los ácaros en la cría sellada, evaluados a las $24 \mathrm{~h}$ y $72 \mathrm{~h}$ posterior a la primera y segunda aplicación del timol, se encontraron muertos. Asimismo la mayoría de protoninfas y deutoninfas, se encontraba en condiciones viables, con apariencia uniforme (turgentes) y movimiento de las extremidades, con mortalidad en ambos estadios menor al $10 \%$. Por otra parte, se presentó un 33\% de mortalidad en las hembras (hijas adultas) (Cuadro 4).

Mortalidad natural: En la colmena testigo ocurrió mortalidad del ácaro madre y su descendencia en una proporción baja. La mortalidad natural del ácaro madre correspondió a un 7\%, mientras que en los estadios inmaduros y las hembras, fue menor al $6 \%$. Por otra parte, la mayor mortalidad se determinó en el macho (Cuadro 4).

\section{DISCUSIÓN}

A la fecha se han realizado algunos estudios para determinar la efectividad del ácido fórmico y timol en el combate del ácaro varroa en abejas africanizadas en Costa Rica. Sin embargo, el método de aplicación del ácido fórmico ha sido principalmente en materiales absorbentes, como el cartón, y en el caso del timol se ha aplicado en forma de cristales sólidos. En el presente estudio se utilizó ácido fórmico y timol en una formulación en gel.

Acido fórmico: La efectividad del ácido fórmico en el tratamiento de varroa obtenida en el presente estudio $(94,7 \%)$, es similar a la reportada en otros países como Argentina, donde se indica una efectividad entre el 92\% y 94\% (Eguaras 2003, Eguaras et ál. 2003). Por otro lado, Calderone (2010) en un estudio realizado en los Estados Unidos, logró eliminar un $60 \%$ de los ácaros con una formulación de ácido fórmico en gel al $65 \%$. Además, en otro estudio realizado con abejas africanizadas en condiciones tropicales, con aplicaciones de ácido fórmico líquido impregnado en un cartón absorbente $(15 \mathrm{ml}$ de ácido fórmico al $85 \%$ vol./vol.), se obtuvo una efectividad del 60,9\% (Calderón et ál. 1999).

La mayor parte de ácaros fueron eliminados durante la primera semana de aplicación del ácido fórmico, especialmente al inicio (24 h). Lo cual coincide con lo citado por Giovenazzo y Dubreuil (2011), quienes observaron que los niveles de evaporación del ácido fórmico y la mortalidad de ácaros fueron elevados durante el primer día de aplicación. Otros estudios mencionan que la mayor cantidad de ácaros muere en la primera semana de tratamiento (Bahreini et ál. 2004, Satta et ál. 2005), lo anterior indica que 
los vapores del ácido fórmico actúan de forma rápida sobre los ácaros presentes en las abejas adultas (foréticos). Se debe mencionar que el efecto del ácido fórmico está relacionado con la actividad y la población de abejas (Mitchell y Vanderdussen 2010). Según González et ál. (2005), al aplicar el ácido fórmico las abejas aumentan la actividad de ventilación, lo cual contribuye a una homogénea distribución de los vapores del ácido en la colmena.

Una de las propiedades de la matriz de gel es que permite una liberación lenta del ácido fórmico, con una concentración adecuada (10 ppm) en la colmena (Eguaras et ál. 2001a), por un periodo aproximado de 3 a 7 días (Villalobos 2010). Este método de aplicación mejora la efectividad del ácido en el combate de varroa y a su vez reduce la cantidad de aplicaciones comparado con presentaciones en forma líquida (Eguaras et ál. 2003).

En este estudio se determinó que en un grupo de colmenas la mortalidad de ácaros se presentó principalmente en el primer día. En estas colmenas, probablemente la mayor cantidad de ácaros se encontraba sobre las abejas adultas, obteniéndose un efecto más visible del ácido sobre varroa, ya que los ácaros sobre las abejas mueren y son observados en el fondo de la colmena a las pocas horas de iniciado el tratamiento. En otro grupo de colmenas, se observó 2 periodos de mortalidad de ácaros, al inicio y al día 15 de aplicación del ácido fórmico. En estas colmenas, probablemente una importante cantidad de ácaros se encontraba en periodo forético, mientras que otros ácaros estaban en la cría sellada.

Respecto al ciclo de varroa, los ácaros permanecen un tiempo sobre las abejas adultas (fase forética), posteriormente ingresan a una celda con cría para llevar a cabo su reproducción (Vandame 2000, Calis et ál. 1998). En colmenas con poca cría o ausencia de cría, el ácaro se mantiene por un tiempo prolongado en las abejas adultas (Bailey y Ball 1991). Por otro lado, en colmenas con presencia de cría se ha indicado que la mayoría de ácaros se encuentra reproduciéndose en las celdas selladas (Amrine et ál. 2007).
Timol: En este estudio la efectividad del timol en el combate de varroa fue de un $96,9 \%$, la cual es similar a la registrada por Loucif-ayad et ál. (2010), quienes obtuvieron un 95\% de mortalidad de varroa al aplicar 12,5 g de Apiguard $^{\circledR}$. Por otra parte, Gregorc y Planinc (2005) señalan únicamente un $46 \%$ de efectividad con $25 \mathrm{~g}$ de Apiguard ${ }^{\circledR}$, en condiciones de bajas temperaturas.

Al aplicar timol se observó una baja mortalidad de ácaros durante las primeras $24 \mathrm{~h}$, la cual aumentó de manera progresiva hasta alcanzar la mayor mortalidad al día 8 de tratamiento. En otros estudios se ha indicado igualmente que la principal mortalidad de ácaros ocurre durante la primera semana, que se incrementan nuevamente en la tercera semana, lo cual coincide con la segunda aplicación del timol (Loucif-ayad et ál. 2010).

Se ha mencionado que el timol en gel tiene mayor eficacia cuando las abejas tienen contacto directo con el producto. Cuando se obstaculiza la remoción del gel, la efectividad disminuye de manera considerable (Palmeri et ál. 2007). Además Baggio et ál. (2004), señalan que la efectividad del Apiguard ${ }^{\circledR}$ depende de la actividad de la colonia, ya que su acción se basa principalmente en la remoción activa del gel por parte de las abejas. Al realizar la segunda aplicación de timol, se observó un nuevo aumento en la mortalidad de varroa. En la mayoría de estudios se realizan 2 aplicaciones de Apiguard $^{\circledR}$, con la finalidad de tener una alta efectividad en el combate de varroa (Baggio et ál. 2004, Gregorc y Planinc 2005, Palmeri et ál. 2007).

Mortalidad natural de varroa: En este estudio un $25,7 \%$ de los ácaros cayeron naturalmente en las colmenas testigo durante los 30 días de evaluación de los tratamientos. Esta mortalidad de varroa es similar a la obtenida por Espinosa y Guzmán (2007) en México con abejas africanizadas, quienes indicaron un $21,9 \%$ de ácaros caídos en el grupo testigo. Por otro lado, Calderón (2011) registró más de un 30\% de ácaros eliminados en colmenas de abejas africanizadas con el uso de la trampa de fondo. 
La mortalidad de ácaros fue notoria en una de las colmenas. Esta colmena tenía una alta población de abejas y mostraba condiciones de limpiadora, en comparación con las otras colmenas testigo. Estudios realizados en Brasil mencionan que la abeja africanizada, presenta una mayor resistencia o tolerancia al ácaro $V$. destructor que abejas de tipo europeo (Junkes et ál. 2007, Moretto y Leonidas 2003). Esta tolerancia se ha relacionado con ciertos factores, principalmente con el comportamiento higiénico de las abejas (Harbo y Harris 2005, Spivak y Reuter 2001) y el comportamiento de limpieza (Moretto y Leonidas 1999). De acuerdo con Moretto (1997) las abejas africanizadas son 8 veces más eficientes en la remoción de ácaros de su cuerpo mediante el comportamiento de limpieza comparado con abejas europeas, pues logran remover hasta un $31 \%$ de los ácaros de su cuerpo (auto-limpieza y alo-limpieza) (Moretto et ál. 1991).

Mortalidad del ácaro $V$. destructor en celdas con cría sellada de obrera: Para llevar a cabo su reproducción el ácaro $V$. destructor ingresa a una celda con cría (Ritter 2001). Dentro de la celda varroa se encuentra protegido de la mayoría de acaricidas, ya que estos actúan sobre los ácaros en estado forético. Lo anterior es una limitante para el tratamiento, ya que aumenta el periodo de aplicación de los productos (Koeniger y Fuchs 1988).

Se ha señalado que el ácido fórmico es el único acaricida que elimina los ácaros que continúan reproduciéndose en el interior de las celdas con cría (Calderón et ál. 2000b, Calis et ál. 1998). De acuerdo con Eguaras et ál. (2001b), el vapor del ácido fórmico atraviesa el opérculo de la celda que causa la muerte de los ácaros que se encuentran en su interior. En este estudio al aplicar ácido fórmico, se determinó una alta mortalidad de los diferentes estadios de varroa en la cría sellada de obrera, principalmente del ácaro madre. Van Alten et ál. (2009), indicaron un 66\% de mortalidad del ácaro madre al aplicar $150 \mathrm{~g}$ de MAQS ${ }^{\circledR}$, la cual aumentó a un $98 \%$ luego de duplicar la dosis. La mortalidad del ácaro madre reduce el nivel de infestación de las colmenas (Donzé y Guerin 1994).

Se debe resaltar el rápido efecto del ácido fórmico sobre varroa, ya que al revisar las celdas 24 h después de su aplicación, se determinó una mortalidad evidente de ácaros. Lo anterior corresponde con lo observado por Calderón et ál. (2000b) y Van Alten et ál. (2009), quienes indicaron mortalidad de varroa en la cría sellada 3 días después de su aplicación. Por otra parte, se determinó una alta mortalidad del macho de varroa, lo cual va a aumentar la cantidad de hembras infértiles en la población de varroa (Martin et ál. 1997).

Timol: A la fecha no hay estudios que indiquen que el timol tiene un efecto directo sobre los ácaros en la cría sellada. Lo anterior corresponde con lo observado en el presente estudio, en el cual se determinó una mortalidad inferior al $10 \%$ del ácaro madre y su descendencia en la cría sellada luego de aplicar el timol. Como se indicó anteriormente, uno de los principales mecanismos de acción del Apiguard $^{\circledR}$, es por medio del comportamiento social de las abejas, las cuales entran en contacto con el producto, lo distribuyen al resto de la colmena y de esta manera entra en contacto con los ácaros foréticos (Baggio et ál. 2004, Palmeri et ál. 2007).

Mortalidad natural: En condiciones naturales ocurre mortalidad de varroa en la cría sellada, tanto del ácaro madre como de la descendencia. Esta mortalidad puede relacionarse con la competencia que se da entre los diferentes estadios por alcanzar el sitio de alimentación en la pupa, que afecta principalmente a los estadios inmaduros (Martin 1994). Asimismo, se menciona que el tamaño de la celda de obrera afecta la viabilidad de la cría inmadura, debido a que el espacio disponible es limitado (Donzé y Guerin 1994).

El macho fue el estadio con mayor porcentaje de mortalidad natural. Lo anterior concuerda con lo obtenido por Ureña (2009), quien obtuvo una mortalidad del $23,9 \%$ en el macho de varroa. La mortalidad del macho podría deberse a la 
falta de alimentación, ya que algunos autores indican que el aparato bucal esta modificado para la transferencia de espermatozoides (Ritter 2001). De acuerdo con Martin et ál. (1997), los estadios del ácaro que no logran ubicar el sitio de alimentación o que no lo utilizan, eventualmente mueren.

\section{CONCLUSIONES}

En conclusión se puede indicar que el ácido fórmico y el timol mostraron una alta efectividad en el combate del ácaro $V$. destructor en colmenas de abejas africanizadas bajo condiciones tropicales, por lo que ambos productos pueden ser considerados como una alternativa en el manejo integrado de varroa. Además, se determinó una alta mortalidad de los diferentes estadios del ácaro en la cría sellada de obrera luego de aplicar ácido fórmico, al ser el ácaro madre y el macho, los estadios con mayor mortalidad. Mientras que en las colmenas tratadas con timol y el grupo testigo la mortalidad de ácaros en la cría sellada fue considerablemente menor.

\section{AGRADECIMIENTOS}

Deseamos agradecer a David VanderDussen, representante de NOD Apiary Products Ltd. - Canadá por la donación del MAQS para evaluación, asi como a Dwayne Mitchell de la Universidad de St. George-Grenada por la visita realizada al CINAT para colaborar en la aplicación del producto MAQS ${ }^{\circledR}$ en colmenas de abejas africanizadas. Además, agradecemos al USDATSTAR-2010-34135-21499 por la cooperación internacional. Asimismo, a Guillermo Ramírez Arias, por la colaboración en el manejo de las colmenas del CINAT durante el estudio.

\section{LITERATURA CITADA}

ADAMCZYK S., LÁZARO R., PÉREZ-ARQUILLUÉ C., CONCHELLO P., HERRERA A. 2005. Evaluation of residues of essential oil components in honey after different anti-Varroa treatments. Journal of Agricultural and Food Chemistry 53:10085-10090.

AL-RIFAI J., AKEEL N. 1997. Determination of pesticide residues in imported and locally produced honey in Jordan. Journal of Apicultural Research 36:155-161.

AMRINE J., NOEL R., WEBB D. 2007. Results of 50\% formic acid fumigation of honey bee hives [Apis mellifera ligustica (Hymenoptera: Apidae)] to control varroa mites (Acari: varroidae) in brood combs in Florida, U.S.A. International Journal of Acarology 2:99-109.

BAGGIO A., ARCULEO P., NANETTI A., MARINELLI E., MUTINELLI F. 2004. Field trials with different thymol-based products for the control of Varroosis. American Bee Journal 144:395-400.

BAHREINI R., TAHMASEBI G., NOWZARI J., TALEBI M. 2004. A study of the efficacy of formic acid in controlling Varroa destructor and its correlation with temperature in Iran. Journal of Apicultural Research 43:158-161.

BAILEY L., BALL B. 1991. Honey Bee Pathology. 2 ed. Academic Press, London, UK. 193 p.

BOGDANOV S. 2006. Contaminants of bee products. Apidologie 37:1-18.

BÜCHLER R., BERG S., LE CONTE Y. 2010. Breeding for resistance to Varroa destructor in Europe. Apidologie 41:393-408.

CALDERÓN R.A. 2009. Diagnóstico de enfermedades de la cría en abejas africanizadas en Costa Rica. Memorias del X Congreso Nacional de Apicultura: Apicultura y su impacto en la seguridad alimentaria. San José, CR. 66 p.

CALDERÓN R.A. 2011. Reducción de la población de ácaros de varroa en colmenas de abejas Africanizadas utilizando una trampa de fondo. Boletín de Parasitología 12:2-4.

CALDERÓN R.A., ARCE H., VAN VEEN J. 1998. Detección, distribución y control de Varroa jacobsoni Oudemans en Costa Rica. Ciencias Veterinarias 21:31-40.

CALDERÓN R.A., FALLAS N., SÁNCHEZ L. 2007. Detección de enfermedades en abejas Africanizadas en Costa Rica. Ciencias Veterinarias 25:335-348.

CALDERÓN R.A., ORTIZ R., ARCE H., VAN VEEN J., QUAN J. 2000b. Effectiveness of formic acid on varroa mortality in capped brood cells of Africanized honey bees. Journal of Apicultural Research 39:177-179.

CALDERÓN R.A., ORTIZ R., SÁNCHEZ L., LALAMA K. 2000a. Control del ácaro Varroa jacobsoni en abejas melíferas (Apis mellifera) bajo condiciones tropicales. Ciencias Veterinarias 23:45-55.

CALDERÓN R.A., VAN VEEN J., ARCE H., RAMÍREZ M. 1999. Use of formic acid for varroa mites control in the tropical conditions of Costa Rica. Ciencias Veterinarias 22:21-27. 
CALDERONE N. 2010. Evaluation of Mite-Away-II ${ }^{\mathrm{TM}}$ for fall control of Varroa destructor (Acari:Varroidae) in colonies of the honey bee Apis mellifera (Hymenoptera: Apidae) in the northeastern USA. Experimental and Applied Acarology 50:123-132.

CALIS J., BOOT W., BEETSMA J., VAN DEN EIJNDE J., RUIJTER A., VAN DER STEEN J. 1998. Control of varroa combining trapping in honey bee worker brood with formic acid treatment of the capped brood outside the colony: putting knowledge on brood cell invasion into practice. Journal of Apicultural Research 37:205-215.

DONZÉ G., GUERIN P. 1994. Behavioral attributes and parental care of varroa mites parasiting honey bee brood. Behavioral Ecology and Sociobiology 34:305-319.

EGUARAS M. 2003. El ácido fórmico como agente de control de Varroa destructor en Argentina. Vida Apícola 122:36-42.

EGUARAS M., DEL HOYO M., PALACIO M., RUFFINENGO S., BEDASCARRASBURE E. 2001a. A new product with formic acid for Varroa jacobsoni Oud. Control in Argentina. I. Efficacy. The Journal of Veterinary Medical Science 48:11-14.

EGUARAS M., LABATTAGLIA M., FAVERIN C., DEL HOYO M., PALACIO M., CARRIN A., RUFFINENGO S., BEDASCARRABURE E. 2001b. Varroa jacobsoni control with formic acid used in different application ways in subtropical and temperate climates. Apiacta 36:97-101.

EGUARAS M., PALACIO M., FAVERIN C., BASUALDO M., DEL HOYO M., VELIS G., BEDASCARRASBURE E. 2003. Efficacy of formic acid in gel for varroa control in Apis mellifera L.: importance of the dispenser position inside the hive. Veterinary Parasitology 111:241-245.

EMSEN B., GUZMÁN-NOVOA E., KELLY P. 2007. The effect of three methods of application on the efficacy of thymol and oxalic acid for the fall control of the honey bee parasitic mite Varroa destructor in a northern climate. Journal of Apicultural Research 147:535-539.

ESPINA D., ORDETX G. 1984. Apicultura tropical. Tecnológica de Costa Rica, Cartago, CR. 506 p.

ESPINOSA L., GUZMÁN E. 2007. Eficacia de dos acaricidas naturales, ácido fórmico y timol, para el control del ácaro Varroa destructor de las abejas (Apis mellifera L.) en Villa Guerrero, Estado de México, MX. Veterinaria México 38:9-19.

FELDLAUFER M., PETTIS J., KOCHANSKY J., SHIMANUKI H. 1997. A gel formulation of formic acid for the control of parasitic mites of honey bees. American Bee Journal 137:661-663.

GIOVENAZZO P., DUBREUIL P. 2011. Evaluation of spring organic treatments against Varroa destructor (Acari: Varroidae) in honey bee Apis mellifera
(Hymenoptera: Apidae) colonies in eastern Canada. Experimental and Applied Acarology 55:65-76.

GONZÁLEZ A., ABARCA D., MARCANGELI J., MORENO L., AGUAYO O. 2005. Comparación de la eficacia del ácido fórmico y del fluvalinato, como métodos de control de Varroa destructor (Acari: Varroidae) en colmenas de Apis mellifera (Hymenoptera: Apidae), en Nuble, centro sur de Chile. Revista de la Sociedad Entomológica Argentina 64:35-42.

GREGORC A., PLANINC I. 2005. The control of Varroa destructor in honey bee colonies using the thymolbased acaricide- Apiguard. American Bee Journal 145:672-675.

HARBO J., HARRIS J. 2005. Suppressed mite reproduction explained by the behavior of adult bees. Journal of Apicultural Research 44:21-23.

IFANTIDIS M.D. 1997. Ontogenesis of Varroa jacobsoni Oud. In Cahiers Options Méditerranéennes. Varroosis in the Mediterranean region. CIHEAM, Zaragosa, ES. p 13-21.

JUNKES L., VIEIRA J., GUERRA J., MORETTO G. 2007. Varroa destructor mite mortality rate according to the amount of worker brood in Africanized honey bee (Apis mellifera L.) colonies. Acta Scientiarum Biological Sciences 29:305-308.

KANGA L., ADAMCZYK J., MARSHALL K., COX R. 2010. Monitoring for resistance to organophosphorus and pyrethroid insecticides in varroa mite populations. Journal of Economic Entomology 5:1797-1802.

KOENIGER N., FUCHS S. 1988. Control of Varroa jacobsoni Oud. in honeybee colonies containing sealed brood cells. Apidologie 19:117-130.

LOUCIF-AYAD W., ARIBI N., SMAGGHE G., SOLTANI N. 2010. Comparative effectiveness of some acaricides used to control Varroa destructor (Mesostigmata: Varroidae) in Algeria. African Entomology 18:259266.

MARTIN S. 1994. Ontogenesis of the mite Varroa jacobsoni Oud in worker brood of the honeybee Apis mellifera L. under natural conditions. Experimental and Applied Acarology 18:87-100.

MARTIN S. 1995. Ontogenesis of the mite Varroa jacobsoni Oud in drone brood of the honeybee Apis mellifera L. under natural conditions. Experimental and Applied Acarology 19:199-210.

MARTIN S., HOLLAND K., MURRAY M. 1997. Nonreproduction in the honey bee mite Varroa jacobsoni in honey bee (Apis mellifera) colonies. Journal of Apicultural Research 36:113-123.

MILANI N. 1995. The resistance of Varroa jacobsoni Oud to pyrethroids: a laboratory assay. Apidologie 23:257-272.

MITCHELL D., VANDERDUSSEN D. 2010. Mite away quick strip $^{\mathrm{TM}}$ mite honey flow efficacy trial. American Bee Journal 150:487-489. 
MORETTO G. 1997. Defense of Africanized bee workers against the mite Varroa jacobsoni in Southern Brazil. American Bee Journal 137:746-747.

MORETTO G., GONCALVES L., DE JONG D. 1991. Africanized bees are more efficient at removing Varroa jacobsoni, preliminary data. American Bee Journal 131:434.

MORETTO G., LEONIDAS J. 1999. Varroa jacobsoni infestation of adult Africanized and Italian honey bees (Apis mellifera) in mixed colonies in Brazil. Genetics and Molecular Biology 22:321-323.

MORETTO G., LEONIDAS J. 2003. Infestation and distribution of the mite Varroa destructor in colonies of Africanized bees. Brazilian Journal of Biology 63:83-86.

PALMERI V., CAMPOLO O., ZAPPALA L. 2007. Evaluation of two methods for applying Apiguard ${ }^{\circledR}$ in an area with continuos nectar flows and brood rearing. Journal of Apicultural Research 46:105-109.

RINDERER T., HARRIS J., HUNT G., GUZMAN L. 2010. Breeding for resistance to Varroa destructor in North America. Apidologie 41:409-424.

RITTER W. 1993. Chemical control: options and problems. In Matheson A. (ed) Living with varroa. The International Bee Research Association (IBRA), Cardiff, UK. p. 17-24.

RITTER W. 2001. Enfermedades de las abejas. Acribia, Zaragoza, ES. 146 p.

SATTA A., FLORIS I., EGUARAS M., CABRAS P., GARAU V., MELIS M. 2005. Formic acid-based treatments for control of Varroa destructor in a mediterranean area. Journal of Economic Entomology 98:267-273.
SPIVAK M., REUTER G. 2001. Varroa destructor infestation in untreated honey bee (Hymenoptera: Apidae) colonies selected for hygienic behavior. Journal of Economic Entomology 94:326-331.

TROUILLER J. 1998. Monitoring Varroa jacobsoni resistance to pyrethroids in western Europe. Apidologie 29:537-546.

TROUILLER J. 2004. Apiguard: an instrument adapted to many beekeeping conditions. Apiacta 38:328-333.

TSIGOURI A., MENKISSOGLU-SPIROUDI U., THRASYVOULOU A., DIAMANTIDIS G. 2003. Fluvalinate residues in greek honey and beeswax. Apiacta 38:50-53.

UREÑA S. 2009. Reproducción del ácaro Varroa destructor (Mesostigmata: Varroidae) en celdas de cría de obrera y zángano en abejas africanizadas (Apis mellifera). Tesis de licenciatura, Universidad Nacional, Heredia, Costa Rica. 64 p.

VAN ALTEN A., TAM J., KEMPERS M. 2009. Winter colony health assessment after using Mite Away ${ }^{\mathrm{TM}}$ Quick Strip (MAQS ${ }^{\mathrm{TM}}$ ) as a control for varroa mites in the fall of 2009. Ontario Beekeepers association, CA. 5 p.

VANDAME R. 2000. Control alternativo de varroa en apicultura. El Colegio de la Frontera Sur (ECOSUR). Chiapas, MX. 30 p.

VILLALOBOS E. 2010. Varroa treatment recommendations with formic acid. University of Hawaii, honey bee varroa mite project. Hawaii, US. 4 p.

WALLNER K. 1999. Varroacides and their residues in bee products. Apidologie 30:235-248. 